\title{
Inability to demonstrate fish-to-fish transmission of Ichthyophonus from laboratory infected Pacific herring Clupea pallasii to naïve conspecifics
}

\author{
J. L. Gregg ${ }^{1, *}$, C. A. Grady ${ }^{1}$, C. S. Friedman ${ }^{2}$, P. K. Hershberger ${ }^{1}$ \\ ${ }^{1}$ Marrowstone Marine Field Station, Western Fisheries Research Center, US Geological Survey, \\ 616 Marrowstone Point Road, Nordland, Washington 98358, USA \\ ${ }^{2}$ School of Aquatic and Fishery Sciences, University of Washington, Box 355020, Seattle, Washington 98195, USA
}

\begin{abstract}
The parasite Ichthyophonus is enzootic in many marine fish populations of the northern Atlantic and Pacific Oceans. Forage fishes are a likely source of infection for higher trophic level predators; however, the processes that maintain Ichthyophonus in forage fish populations (primarily clupeids) are not well understood. Lack of an identified intermediate host has led to the convenient hypothesis that the parasite can be maintained within populations of schooling fishes by waterborne fish-to-fish transmission. To test this hypothesis we established Ichthyophonus infections in Age-1 and young-of-the-year (YOY) Pacific herring Clupea pallasii (Valenciennes) via intraperitoneal (IP) injection and cohabitated these donors with naïve conspecifics (sentinels) in the laboratory. IP injections established infection in 75 to $84 \%$ of donor herring, and this exposure led to clinical disease and mortality in the YOY cohort. However, after cohabitation for $113 \mathrm{~d}$ no infections were detected in naïve sentinels. These data do not preclude the possibility of fishto-fish transmission, but they do suggest that other transmission processes are necessary to maintain Ichthyophonus in wild Pacific herring populations.
\end{abstract}

KEY WORDS: Ichthyophonus · Pacific herring $\cdot$ Horizontal transmission $\cdot$ Parasite

Resale or republication not permitted without written consent of the publisher

\section{INTRODUCTION}

Intraspecific horizontal transmission of the mesomycetozoean parasite Ichthyophonus ${ }^{1}$ has been in question since the earliest reports of epizootics in Atlantic herring Clupea harengus Linnaeus. In his description of a 1914 epizootic in the Gulf of St. Lawrence, Cox (1916) speculated that the route of

1Phenotypic (Hershberger et al. 2008) and genotypic (Criscione et al. 2002, Rasmussen et al. 2010) differences have been identified among isolations of Ichthyophonus hoferi from the northeastern Pacific, suggesting that there are multiple sympatric species in the region. Due to this taxonomic uncertainty, we refer here to the parasite by its generic name infection was through the intestinal tract, either directly by ingestion of parasite schizonts or by ingestion of 'animalculae', which act as intermediate hosts. He then supports the latter hypothesis, as fish often died before displaying ulcers at the epithelium, and the numbers of schizonts in the gonads and digestive tract were 'insignificant', suggesting little expression of parasites into the water. Conversely, Fish (1934) described the skin ulcers that occurred in diseased herring during a 1931 epizootic in the Gulf of Maine, and suggested that resting stages of the parasite are liberated from these 'pus pockets' and consumed directly by conspecifics. Although these 2 hypotheses, transmission via an intermediate host and direct waterborne transmission, continue to be discussed in the literature, the route of infection is 
generally considered to be through the lining of the digestive tract, based on studies using other species (Sinderman 1990, McVicar 1999).

Strong evidence suggests that interspecific transmission of Ichthyophonus follows trophic pathways from forage species to larger piscivorous fishes. Successful transmission to several hosts occurs in the laboratory after per os exposure with either infected tissues or schizonts isolated from infected tissues. Infections established in winter flounder Pseudopleuronectes americanus Walbaum after force-feeding schizonts isolated from Atlantic herring (Fish 1934). A number of salmonid species (i.e. rainbow trout Oncorhynchus mykiss Walbaum, Chinook salmon $O$. tshawytscha Walbaum, coho salmon $O$. kisutch Walbaum, and sockeye salmon O. nerka Walbaum) and prickly sculpin Cottus asper Richardson became infected after feeding on macerated viscera of Ichthyophonus-infected rainbow trout (Rucker \& Gustafson 1953, Gustafson \& Rucker 1956). Similarly, feeding tissues of Ichthyophonus-infected Pacific herring Clupea pallasii Valenciennes established infections in Chinook salmon (Jones \& Dawe 2002), lingcod Ophiodon elongates Girard, copper rockfish Sebastes caurinus Richardson and brown rockfish $S$. auriculatus Girard (J. Gregg unpubl. data). The apparent low host specificity of Ichthyophonus and the ease of interspecific transmission suggest that infections in a number of hosts at higher trophic levels may ultimately result from consumption of infected forage species. However, the mode of transmission and the factors that produce epizootics in planktivorous species like Atlantic and Pacific herring are still in question.

To date, exposure modalities that have successfully established Ichthyophonus infections in clupeid species in the laboratory have no natural analogs. Intraperitoneal (IP) injections with isolated schizonts (Kocan et al. 1999, 2010, Gregg et al. 2011) have established infections in Pacific herring, and massive repeated feedings of infected viscera from conspecifics have established infections in Atlantic herring (Sindermann \& Scattergood 1954, Sindermann \& Chenoweth 1993). Neither of these models provides insight into natural infection processes.

Our understanding of the high incident rates that lead to epizootics in schooling fishes such as herring is limited by unsubstantiated assumptions involving natural routes of transmission, including the possibility of direct intraspecific transmission. If fish-to-fish transmission does occur, then density-dependent and environmental factors may drive incidence rate alone. If transmission involves an intermediate host, spatial and temporal overlap with the intermediate host may drive incidence regardless of other factors. The objective of the present study was to determine if fish-to-fish transmission of Ichthyophonus could be demonstrated in the laboratory by cohabitation of infected and naïve Pacific herring.

\section{MATERIALS AND METHODS}

Specific pathogen-free (SPF) Pacific herring were reared in the laboratory, to ensure that no experimental animals had previous exposure to Ichthyophonus. Naturally spawned eggs, collected from Puget Sound, were transported to the Marrowstone Marine Field Station (MMFS, Nordland, WA, USA) where they were incubated in filtered seawater. After hatching, larvae were fed enriched live feeds (i.e. Brachionus plicatilis and Artemia franciscana) and frozen copepods (Cyclop-eeze ${ }^{\mathrm{TM}}$; Argent Chemical Laboratories) until they were large enough to accommodate commercially available salmon feed (Bio Vita Starter, Bio-Oregon). To avoid waterborne introduction of pathogens, ambient seawater was passed through sand and $10 \mu \mathrm{m}$ cartridge filters and irradiated with UV light prior to being delivered to the herring or the live-feed production facility. Two age classes of herring were used: young-of-the-year (YOY) herring were $156 \mathrm{~d}$ post-hatch and Age-1 herring were $477 \mathrm{~d}$ post-hatch at the initiation of the cohabitation experiment. Mean length and weight (measured at the end of the experiment) were $4.3 \mathrm{~g}$ and $70.8 \mathrm{~mm}$ for YOY fish and $27.8 \mathrm{~g}$ and $131 \mathrm{~mm}$ for Age-1 fish, respectively.

Subsets of YOY and Age-1 SPF herring that would act as infected donors were exposed to Ichthyophonus via IP injection. Parasite material for exposure was isolated from 6 infected adult Pacific herring. Explant heart and liver cultures were maintained in Eagle's Minimum Essential Medium (MEM), buffered to $\mathrm{pH} 7.8$ with Tris, and supplemented with fetal bovine serum $(5 \% \mathrm{v} / \mathrm{v})$, penicillin $\left(100 \mathrm{IU} \mathrm{ml}^{-1}\right)$, streptomycin $\left(100 \mathrm{\mu g} \mathrm{ml}^{-1}\right)$, and gentamycin $\left(100 \mu \mathrm{g} \mathrm{ml}^{-1}\right)$. After $11 \mathrm{~d}$ at $15^{\circ} \mathrm{C}$, the cultures were split and moved into fresh medium. Four days later, loose schizonts were separated from host tissue, and schizonts from all cultures were combined in phosphate buffered saline (PBS). Aliquots $(50 \mu \mathrm{l})$ of this suspension, containing a mean of 213 schizonts $(\mathrm{SD}=63)$ and an unquantified number of mononucleated Ichthyophonus cells, were injected into Age-1 and YOY herring. Sterile PBS was injected into Age-1 and YOY herring that would act as donors in control treatments. 
Six days post-exposure (dpe) Ichthyophonus and saline-exposed donors were cohabitated with YOY sentinels (i.e. YOY SPF herring) in round, 760 l tanks (Table 1). Fifty Age-1 Ichthyophonus donors were combined with 194 YOY sentinels, and 50 Age-1 PBS donors were combined with 196 YOY sentinels (Trial 1: Age-1/YOY treatments). One hundred YOY Ichthyophonus donors were combined with 193 YOY sentinels and 100 YOY PBS donors were combined with 198 YOY sentinels (Trial 2: YOY/YOY treatments). These densities $(0.3$ to 0.4 fish $^{-1}$ ) were chosen based on past experience, as they result in continuous organized schooling behavior within the tanks. Cohabitation tanks were supplied with sand-filtered, UV-treated seawater at 8 to $121 \mathrm{~min}^{-1}$ for the duration of the experiment, except on 2 occasions when pump maintenance required the flow to be shut off for $<8 \mathrm{~h}$. Effluent water was treated with sodium hypochlorite prior to discharge. Seawater temperature was recorded with a data logger (Water Temp Pro V2, Onset Computer) upstream of the cohabitation tanks at 30 min intervals. Salinity was measured with a conductivity probe (YSI Model 30) on average 4.4 times per week. Fish were fed an excess of salmon pellet (Bio Vita Fry, Bio-Oregon) 3 times per week. Excess feed was removed from tank bottoms the day after feeding, and mortalities were removed from tanks daily. The experiment was terminated after $113 \mathrm{~d}$ of cohabitation, at which time survivors were euthanized in an overdose of buffered tricaine methanesulfonate (Tricaine-S, Western Chemical) and assayed for Ichthyophonus infection.
Age-1 donor herring were readily distinguishable by size from the YOY naïve sentinels in the Age-1/ YOY cohabitations (Trial 1). This allowed for the direct measurement of infection prevalence in exposed Age-1 donors, and horizontal transmission was demonstrated if any YOY sentinels from this treatment were infected at the end of the study. In contrast, YOY donors were cohabitated with fish from the same stock and were not distinguishable from the naïve sentinels (Trial 2). We chose not to mark the donor or sentinel fish in Trial 2, as the epithelial damage that would occur from a fin clip or visible implanted tag can confound results by either predisposing donors to shed parasites or predisposing sentinels to infection through damaged epidermis. Instead, 2 samples were taken from a colony $(\mathrm{N}=1348)$ of Ichthyophonusexposed herring. One sample $(\mathrm{n}=100)$ was used as infected donors in Trial 2 and the other $(\mathrm{n}=102)$ was held in a separate tank and used to estimate infection prevalence that resulted from IP exposure (Table 1). Fish in the prevalence estimate tank were euthanized and assayed 23 dpe to estimate the prevalence that resulted from the initial exposure, rather than that which may have resulted from subsequent horizontal transmission. Horizontal transmission in Trial 2 would be demonstrated if the number of infected individuals in the cohabitation tank at the end of the study was greater than the upper bound on the $95 \%$ CI of this prevalence estimate. The $95 \%$ CI for a population proportion from a finite population was calculated following Zar (1999).

Infection status was determined for all fish from the Ichthyophonus treatments and the prevalence

Table 1. Clupea pallasii. Summary of Pacific herring stocked into 113 d cohabitation experiments. Age-1 (477 d) and young-ofthe-year (YOY; $156 \mathrm{~d}$ ) donors were exposed to Ichthyophonus by intraperitoneal (IP) injection. The prevalence tank was terminated at $23 \mathrm{~d}$ to estimate infection prevalence that resulted from initial IP exposure. No. of fish infected includes infected mortalities and infected survivors. PBS: phosphate buffered saline; na: not applicable

\begin{tabular}{|c|c|c|c|c|c|c|c|c|}
\hline \multirow[t]{2}{*}{ Treatment } & \multicolumn{2}{|c|}{ No. of fish stocked } & \multicolumn{2}{|c|}{ No. of mortalities } & \multicolumn{2}{|c|}{ No. of survivors } & \multicolumn{2}{|c|}{ No. of fish infected } \\
\hline & Donors & Sentinels & Age-1 & YOY & Age-1 & YOY & Age-1 & YOY \\
\hline \multicolumn{9}{|c|}{ Trial 1: Age-1 donors/YOY sentinels } \\
\hline Ichthyophonus & $49^{\mathrm{a}}$ & 194 & 0 & 19 & 49 & 175 & 37 & 0 \\
\hline PBS (control) & 50 & 196 & 0 & 15 & $50^{\mathrm{b}}$ & $181^{\mathrm{c}}$ & 0 & 0 \\
\hline \multicolumn{9}{|c|}{ Trial 2: YOY donors/YOY sentinels } \\
\hline Ichthyophonus & 100 & 193 & na & 44 & na & $249^{\mathrm{d}}$ & na & 84 \\
\hline PBS (control) & 100 & 198 & na & 27 & na & $271^{\mathrm{e}}$ & na & 0 \\
\hline \multicolumn{9}{|c|}{ Prevalence estimate (YOY) } \\
\hline Ichthyophonus & 102 & 0 & na & 13 & na & 89 & na & $92^{\mathrm{f}}$ \\
\hline \multicolumn{9}{|c|}{ 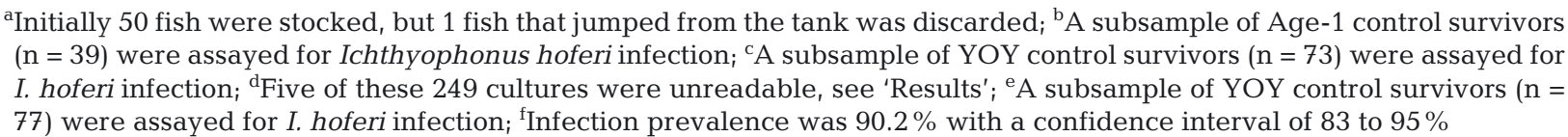 } \\
\hline
\end{tabular}


estimate tank. Mortalities and survivors were assayed by explant culture of the heart and a portion of the liver in MEM. Heart tissue is the most consistent indicator of infection in Pacific herring ( $\mathrm{P}$. Hershberger unpubl. data). We chose to include liver tissue in explant cultures, because this has been identified as an important focus of infection (Reichenbach-Klinke \& Landolt 1973, Rand \& Cone 1990), and on rare occasions we have encountered fish that display positive liver cultures and negative heart cultures. Cultures were held at $15^{\circ} \mathrm{C}$ for $1 \mathrm{wk}$ and examined at $40 \times$ magnification for the presence of Ichthyophonus schizonts or hyphae. A second examination was made $2 \mathrm{wk}$ after dissection. All mortalities and a subset of survivors were similarly assayed from the PBS treatments.

\section{RESULTS}

For Trial 1, no horizontal transmission occurred in the Age-1/YOY cohabitation. In the Ichthyophonus treatment, no mortalities $(\mathrm{n}=19)$ or survivors $(\mathrm{n}=$ 175) among the YOY sentinels cultured positive for Ichthyophonus. Age-1 donors experienced no mortalities, except for 1 fish (discarded) that died after jumping through a small opening in the tank lid. Seventy five percent (37 out of 49 fish) of the remaining Age-1 donors were infected with Ichthyophonus, with 9 of 37 infected fish displaying epidermal ulcers at termination of the experiment. Ichthyophonus was not cultured from any mortalities ( $\mathrm{n}=15$ YOY) or subsampled survivors ( $\mathrm{n}=73$ YOY; $\mathrm{n}=39$ Age- 1 ) in the negative control group.

For Trial 2, horizontal transmission was not detected in the YOY/YOY cohabitation. Twenty-seven of 44 mortalities and 57 of 244 survivors cultured positive for Ichthyophonus (i.e. a total of 84 positive fish). Five survivors were not assayed for Ichthyophonus, as the tissue sample adhered to the side of the culture vessel and was not immersed in the medium. Of the 102 Ichthyophonus-exposed fish in the prevalence estimate tank, 92 cultured positive for Ichthyophonus (12 out of 13 mortalities and 80 out of 89 survivors). This resulted in a prevalence estimate of $90.2 \%$ with a $95 \%$ CI of 83.0 to $95.0 \%$. Therefore, 96 positive fish were necessary to suggest that horizontal transmission occurred in the cohabitation tank. Even with addition of the 5 uncultured survivors to the 84 confirmed positive fish, this threshold was not reached. Ichthyophonus was not cultured from any mortalities ( $\mathrm{n}=27$ YOY) or subsampled survivors $(\mathrm{n}=77$ YOY) in the negative control group.
Temperature decreased during the course of the experiment from a maximum of $11.8^{\circ} \mathrm{C}$ during the first week of cohabitation to a minimum of $7.5^{\circ} \mathrm{C}$ on the final day. Mean temperature for the 4 mo of cohabitation was $9.5^{\circ} \mathrm{C}$. Salinity was relatively unchanged with a mean of 32 ppt, minimum of 29 ppt and maximum of 35 ppt.

\section{DISCUSSION}

With no intermediate host identified, fish-to-fish transmission has become a convenient, parsimonious hypothesis that explains the maintenance of Ichthyophonus in clupeid populations. However, we were unable to demonstrate fish-to-fish transmission of Ichthyophonus in Pacific herring, even with infection pressures (i.e. percentage of infected donors) higher than those typically encountered by wild juvenile herring (Kocan et al. 1999, Hershberger et al. 2002). Fish-to-fish transmission of Ichthyophonus does occur in rainbow trout farms, and has been demonstrated experimentally both by cohabitation (Yokota et al. 2008) and by caging infected rainbow trout upstream of naïve fish (Gustafson \& Rucker 1956). This demonstrates that some waterborne infective stage of Ichthyophonus exists, but the presence of a similar process in the marine environment is still in question. The rainbow trout model not only involves a different host and environment (i.e. freshwater), but also a different strain (or possibly novel species) of Ichthyophonus than that which infects herring (Hershberger et al. 2008, Rasmussen et al. 2010).

The epidermal ulcers that manifest in herring as a result of Ichthyophonus infection have long been considered a possible route for dissemination of infective stages into the surrounding water (Fish 1934, Sindermann \& Scattergood 1954). In Pacific herring, these ulcers do slough viable polykaryotic parasite cells, and these cells are infectious to naïve Pacific herring when administered via IP injection (Kocan et al. 2010). However, multiple attempts made in our laboratory to establish infections in herring by administering these same cells per os have been unsuccessful.

Proof that fish-to-fish transmission does not occur is difficult, but our results suggest that it does not occur readily and likely does not represent the primary mechanism for the maintenance of Ichthyophonus in herring populations. In the late summer and fall, prevalence of infection can reach $6 \%$ in YOY Pacific herring (Kocan et al. 1999) and be as high as $12 \%$ when fish reach Age-1 (Hershberger et al. 2002). If 
fish-to-fish transmission accounts for these infections then some contact between YOY fish and parasites shed from older cohorts is necessary. This exposure of YOY to Ichthyophonus must establish infections, and subsequent amplification within the YOY cohort from a very low prevalence must ensue to account for the trend encountered in the wild.

It is possible that specific conditions, not met in our study, are necessary at the time of exposure to establish Ichthyophonus infections in Pacific herring. Temperature or salinity extremes that occur in small embayments used as nursery habitat for Pacific herring (Norcross et al. 2001) may play a role in the infection cycle. An inverse relationship between temperature and infection rate has been demonstrated in Pacific herring exposed to Ichthyophonus via IP injection (Gregg et al. 2011). However, the current study was conducted over a temperature range (7.5 to $11.8^{\circ} \mathrm{C}$ ) that should not have inhibited infection. The horizontal transmission that occurs among rainbow trout in freshwater (Gustafson \& Rucker 1956, Yokota et al. 2008) suggests that hyposaline environments may facilitate transmission. However, any changes that occur in low salinity which improve infectivity probably occur at the level of the host rather than the parasite, as the facultative survival of Ichthyophonus is greater in the salinities used here than in freshwater (Hershberger et al. 2008). The role of salinity and infectivity with regard to Ichthyophonus remains to be examined, and studies should focus on the rainbow trout model where fish-to-fish transmission has been demonstrated.

Although specific environmental factors may facilitate horizontal transmission of Ichthyophonus, we feel that the inability to detect transmission in this study suggests that an intermediate host, paratenic host or vector may be necessary to establish infections in clupeid and other planktivorous marine species. Parasites that resemble Ichthyophonus have been described in copepods of the genus Calanus (Jepps 1937, Hirche \& Kwasniewski 1997) but an attempt made to culture these Ichthyophonus-like parasites from Calanus spp. suggested that it is not actually Ichthyophonus (Torgersen et al. 2002). Further examination of zooplankters that are common in the diet of Atlantic and Pacific seems a logical next step in the investigation of Ichthyophonus transmission. Because of morphological plasticity in Ichthyophonus life history stages, it is possible that the parasite may present in an unrecognizable form in novel hosts; therefore, zooplankton survey efforts should utilize Ichthyophonus-specific molecular techniques, in addition to culture, in an attempt to identify intermediate hosts or vectors.
Acknowledgements. We thank J. Winton and 3 anonymous reviewers for their comments on this manuscript. We also thank R. Wade and L. Taylor for technical support on this project. Funding was provided by the North Pacific Research Board Project \#1015, Exxon Valdez Oil Spill Trustee Council Project \#10100132-I, and the US Geological Survey Fisheries and Aquatic Resources Program. Experiments involving live animals were conducted under the approval of the University of Washington Institutional Animal Care and Use Committee, Protocol \#4032-04. The use of trade, firm, or corporation names in this publication is for the information and convenience of the reader. Such use does not constitute an official endorsement or approval by the US Department of Interior or the US Geological Survey of any product or service to the exclusion of others that may be suitable.

\section{LITERATURE CITED}

Cox P (1916) Investigation of a disease of the herring (Clupea harengus) in the Gulf of St. Lawrence, 1914. Contrib Can Biol Fish 1914:81-85

Criscione CD, Watral V, Whipps CM, Blouin MS, Jones SRM, Kent ML (2002) Ribosomal DNA sequences indicate isolated populations of Ichthyophonus hoferi in geographic sympatry in the north-eastern Pacific Ocean. J Fish Dis 25:575-582

Fish FF (1934) A fungus disease in fishes of the Gulf of Maine. Parasitology 26:1-16

Gregg JL, Vollenweider JJ, Grady CA, Heintz RA, Hershberger PK (2011) Effects of environmental temperature on the dynamics of ichthyophoniasis in juvenile Pacific herring (Clupea pallasii). J Parasitol Res 2011:563412

Gustafson PV, Rucker RR (1956) Studies on an Ichthyosporidium infection in fish: transmission and host specificity. Special Scientific Report, Fisheries 166. Fish and Wildlife Service, US Dept Interior, Washington DC

Hershberger PK, Stick K, Bui B, Carroll C and others (2002) Incidence of Ichthyophonus hoferi in Puget Sound fishes and its increase with age of Pacific herring. J Aquat Anim Health 14:50-56

> Hershberger PK, Pacheco CA, Gregg JL, Purcell MK, LaPatra SE (2008) Differential survival of Ichthyophonus isolates indicates parasite adaptation to its host environment. J Parasitol 94:1055-1059

> Hirche HJ, Kwasniewski S (1997) Distribution, reproduction and development of Calanus species in the Northeast water in relation to environmental conditions. J Mar Syst 10:299-317

Jepps MW (1937) On the protozoan parasites of Calanus finmarchicus in the Clyde Sea area. Q J Microsc Sci 79: 589-658

Jones SRM, Dawe SC (2002) Ichthyophonus hoferi Plehn \& Mulsow in British Columbia stocks of Pacific herring, Clupea pallasi Valenciennes, and its infectivity to chinook salmon, Oncorhynchus tshawytscha (Walbaum). J Fish Dis 25:415-421

Kocan RM, Hershberger P, Mehl T, Elder N, Bradley M, Wildermuth D, Stick K (1999) Pathogenicity of Ichthyophonus hoferi for laboratory-reared Pacific herring Clupea pallasi and its early appearance in wild Puget Sound herring. Dis Aquat Org 35:23-29

Kocan RM, Gregg JL, Hershberger PK (2010) Release of infectious cells from epidermal ulcers in Ichthyophonus sp.infected Pacific herring (Clupea pallasii): evidence for multiple mechanisms of transmission. J Parasitol 96:348-352 
McVicar AH (1999) Ichthyophonus and related organisms. In: Woo PTK, Bruno DW (eds) Viral, bacterial and fungal infections. Fish diseases and disorders, Vol 3, 1st edn. CABI, Wallingford, p 661-687

Norcross BL, Brown ED, Foy RJ, Frandsen $M$ and others (2001) A synthesis of the life history and ecology of juvenile Pacific herring in Prince William Sound, Alaska. Fish Oceanogr 10:42-57

Rand TG, Cone DK (1990) Effects of Ichthyophonus hoferi on condition indices and blood chemistry of experimentally infected rainbow trout (Oncorhynchus mykiss). J Wildl Dis 26:323-328

Rasmussen C, Purcell MK, Gregg JL, LaPatra SE, Winton JR, Hershberger PK (2010) Sequence analysis of the internal transcribed spacer (ITS) region reveals a novel clade of Ichthyophonus sp. from rainbow trout. Dis Aquat Org 89: 179-183

Reichenbach-Klinke HH, Landolt ML (1973) ReichenbachKlinke's fish pathology: a guide to the recognition and treatment of diseases and injuries of fishes, with emphasis on environmental and pollution problems. T.F.H. Publications, Neptune City, NJ

Editorial responsibility: David Bruno,

Aberdeen, UK
Rucker RR, Gustafson PV (1953) An epizootic among rainbow trout. Prog Fish-Cult 15:179-181

Sinderman CJ (ed) (1990) Fungi. In: Diseases of marine fish. Principal diseases of marine fish and shellfish, Vol 1, 2nd edn. Academic Press, New York, NY, p 57-78

Sindermann CJ, Chenoweth JF (1993) The fungal pathogen Ichthyophonus hoferi in sea herring, Clupea harengus: a perspective from the western North Atlantic. Int Counc Explor Sea CM 1993/F:41:1-39

Sindermann CJ, Scattergood LW (1954) Diseases of fishes of the western North Atlantic, II. Ichthyosporidium disease of the sea herring (Clupea harengus). Res Bull 19. Dept of Sea Shore Fisheries, Augusta, ME, p 1-40

Torgersen T, Karlsbakk E, Kaartvedt S (2002) Deviating vertical distribution and increased conspicuousness of parasitized Calanus. Limnol Oceanogr 47:1187-1191

> Yokota M, Watanabe S, Hatai K, Kurata O, Furihata M, Usui $\mathrm{T}$ (2008) Transmission of the parasite Ichthyophonus hoferi in cultured rainbow trout and comparison of epidemic models. J Aquat Anim Health 20:207-214

Zar JH (1999) Biostatistical analysis, 4th edn. Prentice-Hall, Upper Saddle River, NJ

Submitted: November 11, 2011; Accepted: February 20, 2012 Proofs received from author(s): May 9, 2012 